\title{
TELEPRESENCE, VR, AR TECHNOLOGIES ON THE EXAMPLE OF 3D-VINCI EXHIBITIONS
}

\author{
Kuvshinov, S., Kharin, K. \& PRYANiChNiKov, V.
}

Abstract: The article discusses the organization of educational space of a new type, where audiovisual digital equipment of various kind and types are installed: virtual promoters, interactive panels and tables, holographic visualization systems, stereo visionarium, augmented and virtual reality technologies, etc. The Museum-workshop "3Da Vinci" was created in Moscow at the Russian State University for the Humanities on the basis of proposed concept. This interdisciplinary, technology-rich environment is used for both engineering and humanities education.

Key words: augmented reality, virtual reality, 3D visualisation, $3 D$ printing, laser cutting technology for robotics, audio-visual technologies, new education technologies.
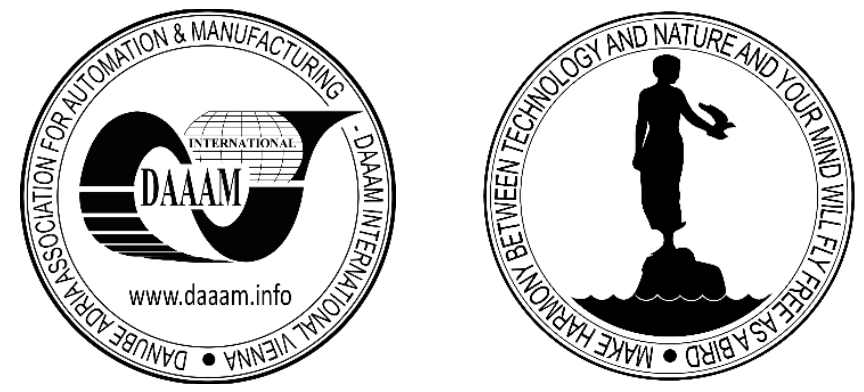

Authors' data: Dipl.-Ing., Dr.techn. Kuvshinov S[ergey]*; Dipl.-Ing. Kharin K[onstantin]* \& Leading researcher, Dr.techn Pryanitchnikov V[alentin]*,** *International Institute for New Educational Technologies RSUH, **KIAM Russian Academy of Sciences, Miusskaya sq. 4 \& 6 Moscow 125047 Russia, kuvshinovs58@mail.ru,v.e.pr@yandex.ru

This Publication has to be referred as: Kuvshinov S[ergey]; Kharin K[onstantin] \& Pryanichnikov V[alentin] (2021). Telepresence, VR, AR Technologies on the Example of 3D-Vinci Exhibitions, Chapter 19 in DAAAM International Scientific Book 2021, pp.231-240, B. Katalinic (Ed.), Published by DAAAM International, ISBN 978-3902734-31-0, ISSN 1726-9687, Vienna, Austria

DOI: $10.2507 /$ daaam.scibook.2021.19 
Kuvshinov, S.; Kharin, K. \& Pryanichnikov, V.: Telepresence, VR, AR Technologi...

\section{Introduction}

In the International Institute for New Educational Technologies RSUH, KIAM Russian Academy of sciences, together with universities and organizations, a complex of works on the creation of intelligent mobile robots for various purposes within the framework of the "Intelligent Robotics" project is carrying out. One of the key problems of such developments is finding proper interfaces with human, with robot's operators and a reliable mechanism for upgrading software and hardware in the conditions of changing versions and meeting the conflicting requirements of various customers. Therefore, when developing such complex software, it is often necessary to use continuous integration and deployment systems to automate the development process. This approach to software development is the most flexible and convenient at the moment. One of the best examples and testing elements are telepresence, VR, AR technologies implemented in 3D-Vinci exhibitions, allows users to arrange virtual interactive tours.

\section{The possibilities of using telepresence technologies and equipment installed}

The paper considers the use of technical means and IT technologies for demonstrating and mastering multi-related materials (users' instructions, expositions) on examples presented in the form of science and education space of the Russian State University for the Humanities - the 3Da Vinci museum-workshop. The museumworkshop 3Da Vinci is not exactly an ordinary educational space. First of all, it was created and is being introduced by the International Institute for New Educational Technologies (IINET RSUH).

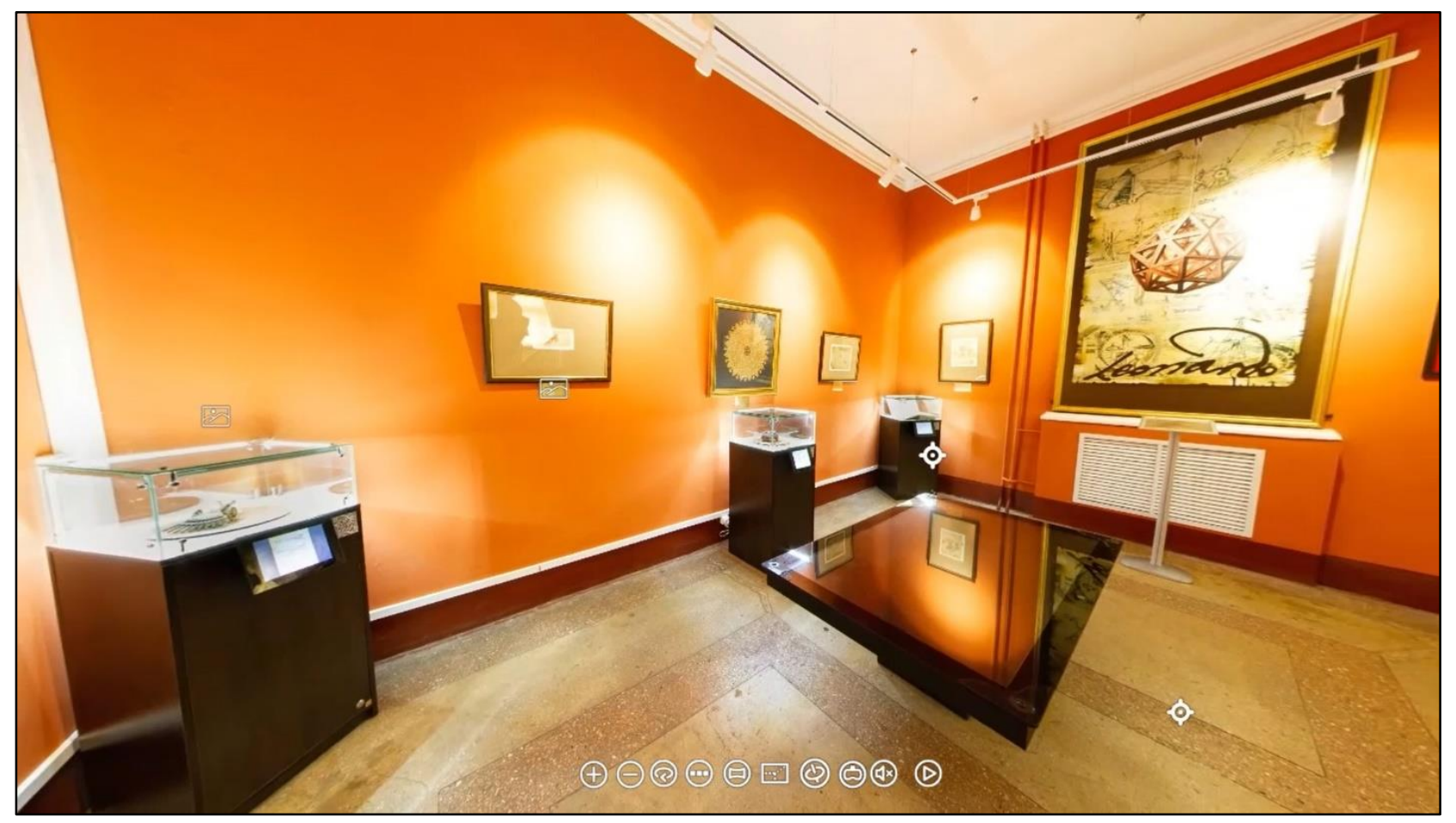

Fig. 1. The view of the exposition in form of virtual tour available in VR. 
Everyone who is enthusiastic about the museum concept can come to RSUH and through their creative activities become full participants in the interdisciplinary activities of the museum-workshop. Secondly, the museum-workshop presents its visitors through a variety of transmission devices: large plasma screens, 7-inch multimedia tablets in front of each exhibit, interactive tables, 3D visualisation systems and holographic installations.

Robotic systems are used for guided tours and remote visits to the exhibition, which has become particularly relevant in times of health and epidemiological restrictions. The panoramic 360photo technology has also made it possible to organise remote access in the form of a virtual tour.

The entrance area plays a major role in all educational environments, as it is some kind of visiting card. In the entrance area of the 3Da Vinci museum-workshop, visitors are greeted by a virtual promoter made in the form of a Leonardo da Vinci figure. The virtual promoter is a silhouette of a person carved out of acrylic and covered with a reverse projection film. A video projector and a computer are used to display the image and play the multimedia content. The welcome message helps set the mood for visitors to interact and set the emotional tone for an interactive visit to the museum-workshop.

The museum's exhibits cannot be classified as classics: fine drawings by Leonardo da Vinci, but in superb facsimile reproductions, magnificent models of machines, mechanisms and devices, but made by three-dimensional printing. All the models were made using digital production technology by students, undergraduate and postgraduate students (these were their personal creative projects) at IINET and - this is the fourth feature of the museum.

In order to present the concept of the museum-workshop more fully, it is necessary to make a short excursion into the history of mastering the scientific and engineering heritage of Leonardo da Vinci, which is the semantic starting point of the museum-workshop activities. The non-trivial and tragic fate of this heritage is widely known. Today we know of just over seven thousands of Leonardo's surviving texts, drawings and sketches. A huge achievement in recent years, primarily the merit of Italian researchers, the publication in one multi-volume edition of all known manuscripts of Leonardo, stored in different places around the world. But the tragic fate of the manuscripts only underscores the far greater tragedy of the entire oeuvre of the consummate master of the High Renaissance. There is no criterion for comparison, but Da Vinci's manuscripts are at least as important as his widely acclaimed paintings. The HoloPro rear projection screen is used to display the master's paintings in high quality.

All his life he intended to organize and publish his notes, but this did not happen. This is the true tragedy of the Master. The accusations of his employers, and some historians, of lack of commitment, inability to work, almost laziness, are ludicrous. One has only to leaf through Leonardo's manuscripts to understand the depth and scale of his industriousness. But it's a different kind of industriousness from Michelangelo's, for example. Leonardo's notes and sketches are impossible to categorise. The first to realise this was Francesco Melzi, preparing his Treatise on Painting. Leonardo da Vinci's manuscripts are the traces of a constant and uninterrupted dialogue with himself, a constant search for truth and harmony, a process Leonardo could not stop, 
Kuvshinov, S.; Kharin, K. \& Pryanichnikov, V.: Telepresence, VR, AR Technologi...

in fact he was this process, a process of life and creativity. This understanding helps to explain much in Da Vinci's behavior, in his uneasy relationship with those around him, and to understand the worthlessness of Freudian analysis of Leonardo's work.

The apparent "diary-like" and even personal nature of Leonardo da Vinci's manuscripts is sometimes forgotten, and many historians begin to judge them as if they were publications prepared by the author himself. Sometimes authors writing about Leonardo as their sensational discovery report Leonardo's lack of independence in certain ideas, direct borrowings, (almost plagiarism), mistakes, etc. But it is not so! Serious historiography has long made documentary comparisons of what, where and from where the facts and data in Leonardo's manuscripts. True, no questions have been posed as to why or for what purpose. The vast majority of researchers focus on describing and analysing the results of Leonardo's work and do not consider the process of his work, where the results, however brilliant, are merely markers of the creative journey.

The classical approach to the study of the creative legacy of an individual begins with an analysis of the source base, which distinguishes two main components: the works of the "hero" of the study and the bibliography - the works about him. The first component of Leonardo's legacy is more or less clear today. They are available in hard copy, now also in translation. The museum-workshop is home to a rare book exhibit on Leonardo's life and work.

All works about Leonardo, even by such prominent authors as Giorgio Vasari, Vasili Zubov and Carlo Pedretti, have the peculiarity, that they are narrative and addressed primarily to specialists. They are therefore characterised by an aspiration towards rigorous scholarship and "objectivity". Which is undoubtedly a good thing. But in these works there is no reader, there is no place for his or her thinking, only to follow the author's reasoning. Therefore, the exposition of the museum-workshop helps to motivate future specialists to study Da Vinci's creative engineering legacy.

Three-dimensional modelling of Leonardo's machines and mechanisms, which are on display in the museum-workshop, can also be considered a new approach. Da Vinci's interactive installations can now be seen in many European cities. They invariably attract great interest and are rightly included in cultural events.

The basis of the 3Da Vinci museum-workshop exhibition is Leonardo da Vinci's engineering designs in three forms of representation: physical models made by 3D printing; and models in augmented and virtual reality. Most of the virtual and all of the physical models, made by the students on a digital technology base, were the final stage in the development of the individual creative projects. This stage was preceded by an introduction to the heritage of Leonardo da Vinci; selection of the theme of the creative project; 3D scanning; 3D modelling; 3D printing; design of the model and, finally, project defence.

There are some software and technological aspects of the organisation of the educational space of the 3Da Vinci museum-workshop. An integral part of a modern museum is the availability of audio guides to the exhibitions. To this end, all of the museum's exhibits are equipped with QR codes, which, when read by visitors' smartphones, redirects them to the "3Da Vinci museum-workshop" resource, created on the Internet using the online service izi.travel/ru. 
This resource makes it possible to create various types of multimedia guidebooks. The multimedia support of the exposition with a developed navigation system makes it possible to get more complete information after visiting the museum and motivate to visit again to identify the nuances of a rather voluminous exposition.

A special place in the exhibition is occupied by the three-dimensional visualisation visionarium, where visitors have the opportunity to 'visit' and actively interact with objects not represented in the main exhibition. A few comments should be made here on the application of virtual reality technologies. First of all, a virtual educational space can be regarded as an educational environment of a fundamentally new type, designed to simulate processes and situations in a wide range of disciplines. It is thought that from the didactic point of view it can claim to be another level of mastering subject and operational fields. In terms of system integration, such a virtual environment represents a new type of educational and research laboratory, which simulates the most complex and diverse situations, from museum expositions to complex technical objects.

\section{Synergy effect of three-dimensional visualization, VR \& AR technologies}

Today, the training of future specialists at training centres and universities is usually conducted in classrooms equipped with computer, projection, audio and video equipment, and interactive visualisation devices, so the use of VR (virtual reality) and AR (augmented reality) is no longer something exotic, but represents a logical continuation of the introduction of high technology in the cultural and educational space.

Specially developed mobile app "3Da Vinci AR" can be downloaded from Apple Store and Google Play app shops and installed to smartphones and tablets. By opening the app and pointing your smartphone camera at the monitor screen, you can get an augmented reality image.

Demonstrations in AR and VR formats of Leonardo da Vinci's reconstructed machines and mechanisms make it possible to introduce young people, future professionals, to the specific perception of the new engineering educational environment. Currently, many of the world's museums are actively using virtual and augmented reality technologies not only to improve the information content of exhibitions, but also to attract visitors with the wow effect, which has a certain commercial success. This begs the question, what additional perceptual possibilities do virtual and augmented reality technologies offer? First of all, it is an "immersion" with the object through 3D, VR and AR technologies. Placing it in a historical or other context, when not only the artefact itself is elaborated, but also the historical environment, which is in harmony with the modern philosophical approach to the study of not only the work, but also the set of meanings, that led to its creation. Secondly, the display of the invisible (for example, what is on the side of a painting (exhibit) or what is inside the object). Whereas in an art exhibition it is rather an attempt to reconstruct or elaborate the artist's concept, in an engineering installation it is an integral part of the construction, showing how it works. 
Thirdly, visual interactivity, such as assembly/disassembly, demonstration of the principles of functioning or use of a particular machine or mechanism. In addition, the museum-workshop offers visitors the opportunity to experience virtual objects from Leonardo da Vinci's work in a VR Cinemizer helmet; a VR museum screening on a projection system in $2 \mathrm{D} / 3 \mathrm{D}$-stereo formats; and interactive movement with 3DConnexion technology (6 degrees of freedom manipulator).

"3Da Vinci AR" mobile app implements augmented reality in the museumworkshop. The essence of the technology is that by arming themselves with smartphones and installing this app, visitors are able to bring their smartphone camera close to images of Da Vinci machines and mechanisms to see animated models on screen. To make it easier to navigate the museum-workshop, a catalogue of exhibits has been produced with facsimile drawings of Leonardo, that "come to life" on smartphone screens.

As an extension of the museum-workshop visitors' experience, the holographic table, by the Russian company Nettle, created using MotionParallax3D technology, is placed in the halls. We use the term "holographic" to refer to the fact, that the proposed imaging technology allows a precise and realistic representation of Leonardo da Vinci's three-dimensional objects from different angles, similar to what has become traditional for specialists holography, where highly stable laser radiation is used to record and reproduce the image. In some sense virtual displays on MotionParallax3D displays are close to the multiplexed holograms designed by Lloyd Cross, but they represent the displayed object much better and this allows them to be seen as complete holograms in the truest sense of the word, as complete optical information about the object.

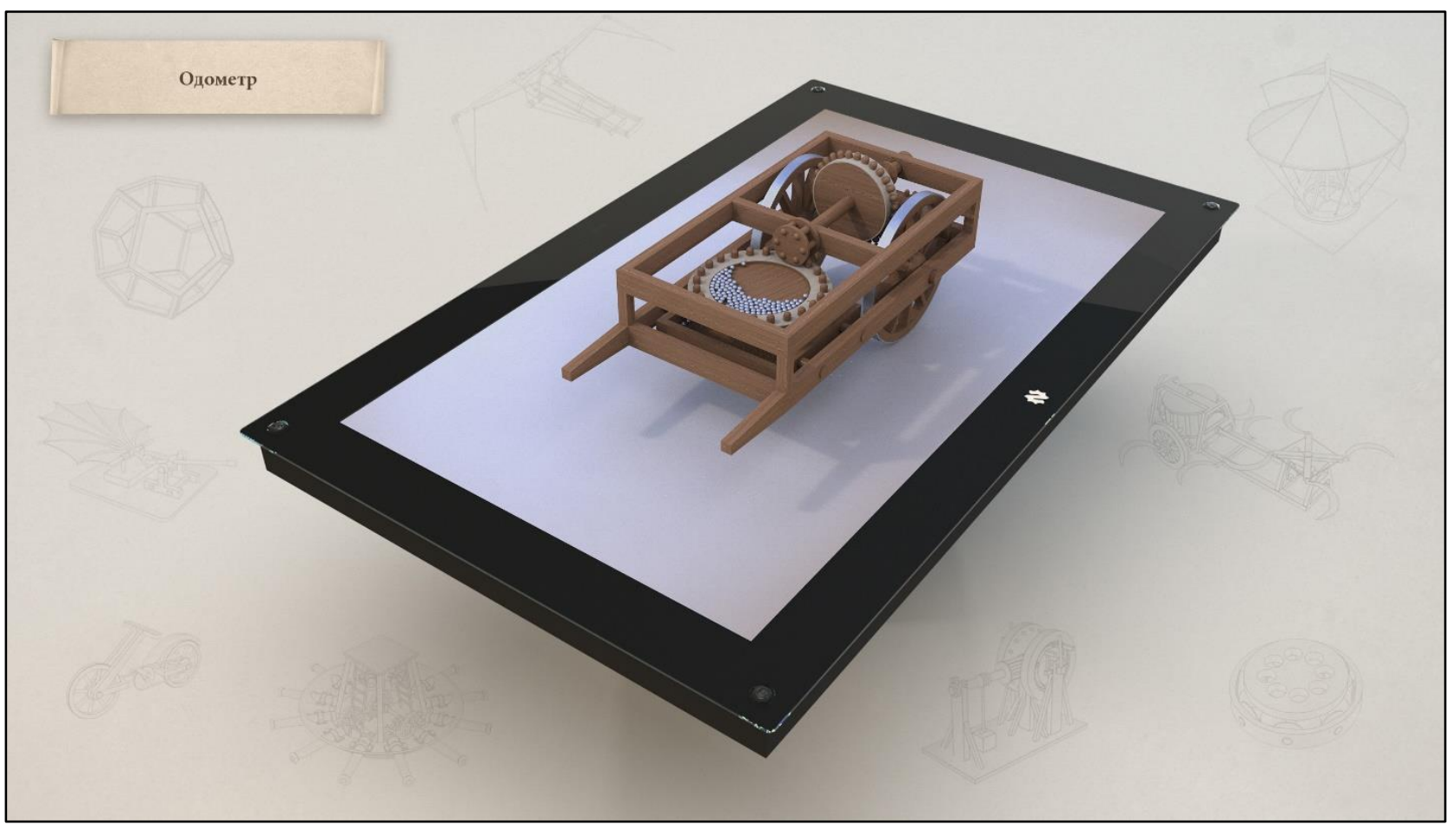

Fig. 2. Model representation (rendering) of an image of a three-dimensional model on a "holographic" table. 
As a result, visitors to the museum-workshop are able to study Da Vinci devices with a highly detailed model; to use the zoom function; to decompose the object, assemble/disassemble into elements; and to view the mechanism as it works.

Projections of virtual objects of Da Vinci machines and mechanisms on the holographic table are calculated in such a way, that the image the visitor sees is fully identical to the image he would see if the virtual objects were real and were located at the corresponding point in real space. In order to build and display correct projections of virtual objects, the virtual reality system requires actual coordinates from which the virtual world is observed.

Specialised 3D shutter glasses with active trackers are used for viewing, by which the system tracks the user's position in space with a high degree of accuracy. Based on the viewer's eye position, the system calculates the projection of the virtual object onto the plane of the screen.

MotionParallax3D technology

MotionParallax3D technology engages both monocular and binocular human vision mechanisms.

\section{ㄷ․}

Motion parallax

When the viewer moves, the viewer's perspective

of the virtual object is rearranged based on the

tracking system

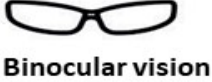

Shutter glasses perform separation of the generated stereoscopic image (active stereo)

\section{Mechanisms of Lag Compensation}

Lag and the resulting distortion of virtual object geometry is a major enemy of virtual reality systems. Nettle's MotionParallax3D technology solves the problem of display lag and takes the stability of virtual objects to a whole new level: virtual objects are visually indistinguishable from real-world objects.

\section{Tracking system}

The technological core of NettleBox is an proprietary tracking system.

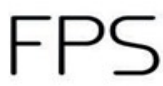

Tracking speed Tracking speeds of up to 900 FPS when operating in normal mode. System response is less than $2 \mathrm{~ms}$

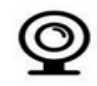

$$
\begin{aligned}
& \text { Camera system } \\
& \text { The } 4 \text { camera system } \\
& \text { guarantees millimetre } \\
& \text { precision and stable } \\
& \text { operation even in aggressive } \\
& \text { light conditions }
\end{aligned}
$$
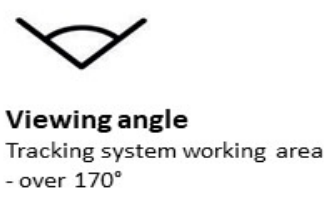

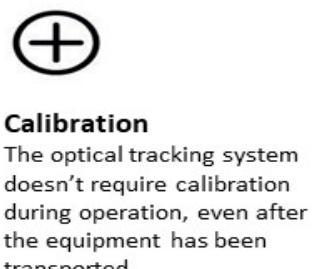

transported

Fig. 3. Key points of "virtual hologram" technology.

Unlike stereo displays, which utilise binocular vision only, MotionParallax3D tables and displays utilise a volume perception mechanism such as motion parallax, i.e. moving parts of an image relative to one another at an angular rate proportional to the distance difference between the parts and the observer, as their relative position changes. This volume perception mechanism is triggered by constantly realigning the image based on the current coordinates of the user's eyes. In this way, virtual objects shift in relation to each other and to visible real objects, following the same laws and principles as real-world objects. This allows the brain to construct a complete picture containing both real and virtual objects with visually indistinguishable behaviour. 
Kuvshinov, S.; Kharin, K. \& Pryanichnikov, V.: Telepresence, VR, AR Technologi...

But by rearranging the real-time projection in this case, objects are perceived as having a certain shape, volume, and distance from the user's eyes, and thus are realistic from all angles. Position and scale of the image on the screen can be controlled by: a traditional computer mouse; a wireless touchpad, tablets and smartphones with various mobile operating systems. The tracking system uses unique Russian-designed cameras with a normal reading rate of up to 900 frames per second. The system of four cameras guarantees millimetre accuracy and stability of operation even in aggressive lighting conditions. The practical experience of using this technology in the 3Da Vinci museum-workshop suggests, that students quickly develop "three-dimensional" thinking, which is very useful for further design and research activities. This is also the base for principally new interfaces in robotics.

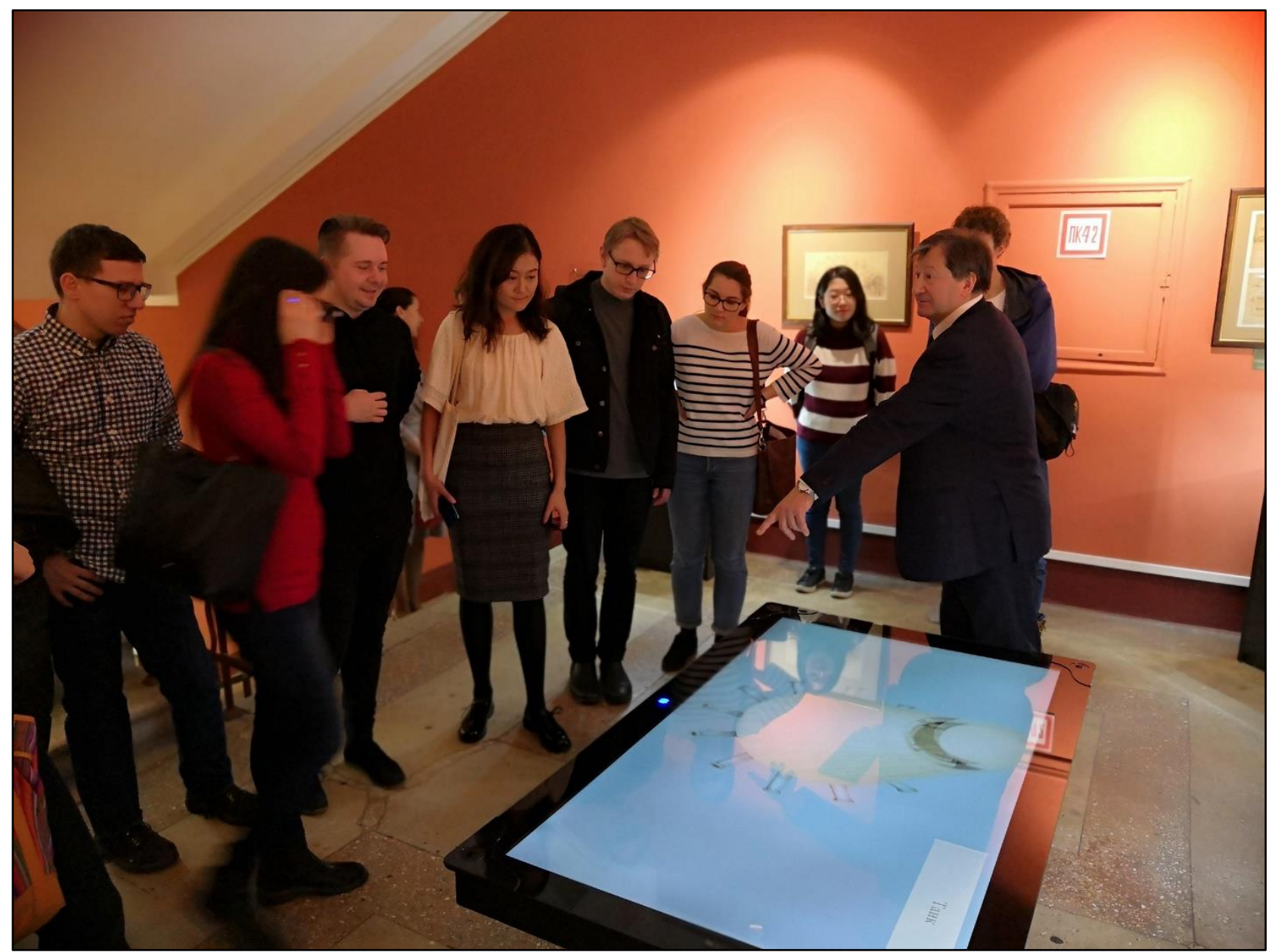

Fig. 4. Demonstration of virtual holographic images of three-dimensional models of machines and mechanisms on a table using MotionParallax3D technology.

One of the main objectives, that the founders of the 3Da Vinci museum-workshop set for themselves, was to motivate future engineers to develop design thinking using the latest digital production technologies. To support this kind of works, they created the educational video course "Leonardo da Vinci in 3D", that could be positioned as an intellectual cognitive quest, a step towards a deeper study of the problems of engineering creativity, to expand their knowledge in the historical, scientific, technical and cultural field. 
In addition, the video course aims to excite the interest of young people to come to the "da Vinci workshop" - the Centre for Technological Support of Education at the RSUH - and realise their creative project. The 'Leonardo da Vinci in 3D' educational course is structured into four modules: "Starting an Idea", "From Idea to Design", "From Design to Construction" and "From Drawings to Digital Production".

After visiting the museum-workshop, students are invited to the University's digital workshops where, using 3D printers, laser cutting and engraving machines, 3D scanners and $\mathrm{CNC}$ machines, they create their own tangible three-dimensional engineering object related to the work of Leonardo da Vinci. Some of the young researchers go further. "Building on Leonardo", they not only follow an engineering path, that Da Vinci did not follow in his designs, but also propose new solutions, that incorporate the "Leonardo spirit" and modern ideas. One of the models on display at the museum-workshop, a model of an ideal city, is just such an amazing combination of the past and the future, the great Master and the Apprentice. In this way, the work at the museum-workshop and the 'three-dimensional stereo mastering' of theoretical material are closely linked with the practical work of forming a three-dimensional material object, and thus a significant step towards creative design and research thinking is made. The developers of the concept work in a general educational and enlightenment paradigm with the corresponding objectives, tasks, methodological support and forms of presentation of materials. This allows the museum-workshop to be widely used in the pedagogical process of professional engineering education.

\section{Conclusion}

As a result, the conducted research made it possible to create the effective interfaces and structured materials, including 3D-tour around exhibitions. An evaluation of the application of visualisation technologies on the example of the 3Da Vinci museum-workshop demonstrates the effectiveness of this approach in at least two main ways. The first is a deeper, systematised, causal perception of the significance of Leonardo da Vinci's scientific and engineering works in a broader socio-cultural context. The second is the mastery of digital technology, not as an end in itself, but as an effective means of deeply and comprehensively exploring the complex processes of scientific and engineering creativity and convincingly presenting the results. We invite everybody to visit our university in Moscow, the International Institute for New Educational Technologies, and to take a fascinating tour in the halls of the 3Da Vinci museum-workshop and test the software and hardware integrated solutions.

\section{References}

Anufrieva. E., Kharin K., Kuvshinov S., Pryanichnikov V. Implementaion of augmented and virtual reality technologies for educational and research situation center. Proceedings of the 28th DAAAM International Symposium, pp. 0361-0366, B. Katalinic (Ed.), Published by DAAAM International, ISBN 978-3-902734-11-2, ISSN 1726-9679, Vienna, Austria. DOI: 10.2507/28th.daaam.proceedings.050 
Kuvshinov, S.; Kharin, K. \& Pryanichnikov, V.: Telepresence, VR, AR Technologi...

Aryskin, A., Bogdanovich, A., Davydov, O., Khelemendik, R., Petrakov, M. \& Pryanichnikov, V. (2019). Control and Interaction Algorithms for Industrial and Service Robots, Chapter 33 in DAAAM International Scientific Book 2019, pp.377384, B. Katalinic (Ed.), Published by DAAAM International, ISBN 978-3-902734-242, ISSN 1726-9687, Vienna, AustriaDOI: 10.2507/daaam.scibook.2019.33

Aryskin, A., Davydov, O., Eprikov S., Ksenzenko A., Pryanichnikov, V., Punenkov O., Shipovalov E., Solovyova M., Stepanova D., Tarasov R. \& Tikhomirov A. (2020). Robotariums implementations witn the Elements of Artificial Intelligence Control, Proceedings of the 31st DAAAM International Symposium, pp.0973-0985, B. Katalinic (Ed.), Published by DAAAM International, ISBN 978-3-902734-29-7, ISSN 1726-9679, Vienna, Austria DOI: 10.2507/31st.daaam.proceedings.135

Davydov D.V., Eprikov S.R., Kirsanov K.B., Pryanichnikov V.E. (2017). Service Robots Integrating Software and Remote Reprogramming, Proceedings of the 28th DAAAM International Symposium, pp.1234-1240, B. Katalinic (Ed.), Published by DAAAM International, ISBN 978-3-902734-11-2, ISSN 1726-9679, Vienna, Austria, DOI: $10.2507 / 28$ th.daaam.proceedings. 172 .

Kuvshinov, S., Kharin, K. Data Visualization on Distributed Display Facilities in a Professional Distance Learning System, Proceedings of the 29th DAAAM International Symposium, pp.0411-0415, B. Katalinic (Ed.), Published by DAAAM International, ISBN 978-3-902734-20-4, ISSN 1726-9679, Vienna, Austria 2018 DOI: 10.2507/29th.daaam.proceedings.060

M. Shahin, M. Ali Babar, and L. Zhu, -Continuous Integration, Delivery and Deployment: A Systematic Review on Approaches, Tools, Challenges and Practices", IEEE Access, 2017. https://arxiv.org/pdf/1703.07019.pdf

Mathematical Models and Software Protection Tools for Distributed Computer Systems Galatenko A.V. abstract of the dissertation for the degree of candidate of Physical and Mathematical Sciences / Institute of System Programming. Moscow, 2004

MotionParallax3D. Available at: https://en.wikipedia.org/wiki/MotionParallax3D (Accessed October, 25 2021).

Pryanichnikov V. E. Artificial intelligence - software and hardware robotic systems. Sc.-Tech Journal Information-measuring and control systems. - 2018. — Vol. 16, No. 12. - Pp. 3-11, ISSN 2070-0814.

R.B. Tarasov, O.I. Davydov, V.E. Pryanichnikov, M.D. Solovyova, A.N. Tikhomirov, E.A. Shapovalov, S.R. Eprikov // Software-Control Shell for Service Robots With Parallel Computing. Extreme robotics. // Collection of abstracts of the 31st International Scientific and Technical Conference "Extreme Robotics". - St. Petersburg: CPI LLC "Polytechnic-print", 2020. - 86 p., pp.41-42. ISBN 978-5-85875602-6.

Ushakov Yu.A., Polezhaev P.N., Shukhman A.E. Creation of a multiservice multipoint VPN network with dynamic auto-tuning. // Bulletin of Orenburg State University. 2015. - No. 9. - pp. 170-178.

V.E. Pryanichnikov, E.A. Shapovalov, R.B. Tarasov // Intellectual Support of Logistics Missions in Medical Institutions with Mobile Service Robots AMUR-307. Extreme robotics. // Collection of abstracts of the 31st International Scientific and Technical Conference "Extreme Robotics". - Saint Petersburg: CPI LLC "Polytechnic-print", 2020. - 86 p., p.73. ISBN 978-5-85875-602-6. 